\title{
Effect of octreotide on gall stone prevalence and gall bladder motility in acromegaly
}

\author{
S M Catnach, J V Anderson, P D Fairclough, R C Trembath, P A J Wilson, E Parker, \\ G M Besser, J A H Wass
}

\begin{abstract}
Octreotide therapy in acromegaly is associated with an increased prevalence of gall stones, which may be the result of an inhibition of gall bladder motility. Gall stone prevalence in untreated acromegalic patients relative to the general population is unknown, however, and the presence of gall stones and gall bladder motility in these patients and in acromegalic patients receiving octreotide was therefore examined. Thirty four percent of 39 patients who had taken octreotide for a mean of 20 months had gall stones compared with $16 \%$ of 38 patients who had not been treated with octreotide $(\mathbf{p}<\mathbf{0 . 0 0 5})$. In a subgroup of 21 patients studied prospectively over 4 to 18 months, two patients developed stones. No patient had symptoms referrable to their gall stones. In 31 untreated acromegalic patients, the mean fasting gall bladder volume was similar to that in normal subjects. Maximal percentage emptying, however, was impaired (34 $v 64 \%, p<0.001)$ and the mean postprandial residual gall bladder volume increased $(21.7 v$ $9.0 \mathrm{ml}, \mathrm{p}<0.001)$. Treatment with octreotide increased the mean postprandial residual volume further to $36.8 \mathrm{ml}(\mathrm{p}<0.001)$. Gall bladder emptying in untreated acromegalic subjects is impaired. Octreotide further increases postprandial residual gall bladder volume and this may be a factor in the increased gall stone prevalence seen in these patients.

(Gut 1993; 34: 270-273)
\end{abstract}

The excessive and autonomous secretion of growth hormone in acromegaly may be reduced by the administration of somatostatin.' The therapeutic value of somatostatin, however, is limited by its very short plasma half life of 3 to 4 minutes. ${ }^{2}$ Octreotide, a long acting somatostatin analogue, is now being used increasingly in the management of acromegalic patients. ${ }^{3}$ Patients with somatostatin producing tumours are known to have a high incidence of gall stone formation, ${ }^{4}$ possibly caused in part by impaired gall bladder emptying consequent upon inhibition of cholecystokinin and motilin, allowing stasis of bile and thence crystal and subsequently stone formation. An increased prevalence of gall stones in acromegalic patients being treated with octreotide has been reported by several groups and it has been postulated that this may also be the result of impaired gall bladder contraction..$^{5-7}$

We have used ultrasonography to assess both the presence of gall bladder stones and parameters of gall bladder emptying in response to a liquid meal in a group of acromegalic patients, on and off octreotide treatment, and compared these patients with a group of normal subjects and a group of non-acromegalic gall stone patients in whom impaired gall bladder motility has been implicated in the pathogenesis of stones.

\section{Subjects and methods}

Nineteen normal volunteers (mean age 37 , range 23-64 years, eight women) were recruited from hospital staff. None had any history of gastrointestinal or gall bladder disease and ultrasonography showed no evidence of gall stones or gall bladder pathology.

Fifty one patients with acromegaly (mean age 48 , range $24-80$ years, 28 women) were studied. The clinical diagnosis of acromegaly was confirmed by a $75 \mathrm{~g}$ glucose tolerance test during which circulating growth hormone failed to fall below $2 \mathrm{mU} / \mathrm{l}$. The average basal serum growth hormone obtained in each patient from a five point day curve performed on samples drawn through an indwelling venous cannula over 12 hours ranged from 5 to $1135 \mathrm{mU} / \mathrm{l}$, and no sample was $<2 \mathrm{mU} / 1$.

Thirteen patients with gall stone disease were also studied. Six aged 43-56 years (one woman) had undergone percutaneous cholecystolithotomy and were free of stones at the time of this study, and seven patients aged 28-78 years (four women) had gall stones in the gall bladder. Ultrasound of the gall bladder after percutaneous cholecystolithotomy showed no evidence of thickening or tethering of the gall bladder wall.

PRESENCE OF GALL STONES

Thirty eight of the patients with acromegaly were studied before treatment with octreotide and 21 of this group with a further 18 patients (total 39) were also studied after taking octreotide for a mean of 10 months (range 3-62 months). Octreotide was administered by subcutaneous injection $(100 \mu \mathrm{g})$ three times daily at 0700,1500 , and 2300 in all but five patients. Three of these five took 600 $\mu \mathrm{g}$, one $400 \mu \mathrm{g}$, and one $360 \mu \mathrm{g} /$ day. The treated and untreated groups of patients were well matched for age and sex (untreated patients, median age 50 years, range $24-79,13$ women; treated patients, median age 48 years, range 25 80,15 women). The expected prevalence of gall stones in the untreated and treated patients was calculated from the population prevalence data in two previously published studies from Bristol, $\mathrm{UK}^{8}$ and Sirmione, Italy. ${ }^{9}$ For each patient, the probability of having gall stones was determined and the sum of the individual probabilities was taken as the expected prevalence for the whole group.

None of the patients or volunteers were taking 
TABLE I Variability in gall bladder size and emptying in 12 normal subjects

\begin{tabular}{lll}
\hline Gall bladder measurement & Mean $(S D)^{\star}$ & $\begin{array}{l}\text { Coefficient of } \\
\text { variation }(\%)\end{array}$ \\
\hline Fasting volume $(\mathrm{ml})$ & $28 \cdot 6(4 \cdot 6)$ & $16 \cdot 1$ \\
Residual volume $(\mathrm{ml})$ & $9 \cdot 0(2 \cdot 4)$ & $27 \cdot 0$ \\
Maximal emptying $(\%)$ & $66 \cdot 0(8 \cdot 1)$ & $12 \cdot 3$ \\
\hline
\end{tabular}

* Standard deviation of differences between values of the duplicate scans.

any other medication and all gave informed consent. The study was approved by the local ethical committee.

\section{Gall bladder motility}

Gall bladder volume and emptying were determined using ultrasonography. ${ }^{10} 11$ Using a 3.5 or $5 \mathrm{MHz}$ transducer, real time ultrasound scans were obtained with an Aloka SSD 500 scanner. Subjects were scanned supine in the right anterior oblique position and the gall bladder was visualised in the longitudinal and transverse planes. Measurements of length (l), width (w), and height $(\mathrm{h})$ of the gall bladder were taken in duplicate. The volume of the gall bladder was subsequently calculated using the ellipsoid method (vol $=\pi / 6 \times \mathrm{lwh}$ ). ${ }^{11}$ In order to determine the reproducibility of our scanning technique, repeat studies, on at least three separate occasions, were performed in 12 of the normal subjects. The coefficient of variation for gall bladder fasting and residual volumes and percentage gall bladder emptying are given in Table I and are similar to those quoted by Everson et al. ${ }^{10}$

Scans were performed at $8 \mathrm{am}$, subjects having fasted for at least 10 hours. The fasting volume (FV) of the gall bladder was determined from the mean of two measurements taken 5 minutes apart. Subjects then ingested $250 \mathrm{ml}$ of Ensure (250 kcal, fat as corn oil, $8.8 \mathrm{~g}$, protein $8.8 \mathrm{~g}$, carbohydrate $34.3 \mathrm{~g}$, Abbott laboratories, England) and the gall bladder was rescanned at 5 minute intervals for 40 minutes or until the gall bladder started to refill. The smallest gall bladder volume observed was termed the residual volume (RV). The maximal percentage emptying $(\% \mathrm{E})$ was calculated using the formula $(1-\mathrm{RV} / \mathrm{FV}) \times 100$. The rate constant of gall bladder emptying was calculated from $\ln /$ linear regression of gall bladder volume $v$ time. ${ }^{12}$

Acromegalic patients taking octreotide administered the first daily injection 1 hour before the scan. The radiologist was unaware which acromegalic subjects were taking octreotide.

Gall bladder motility studies were performed in 31 patients before treatment with octreotide, and in nine of this group with a further six patients (total 15) also after treatment with octreotide.

TABLE II Prevalence of gall stones in untreated acromegalic patients and those treated with octreotide studied prospectively and retrospectively. Medians and ranges of duration of therapy with octreotide are given

\begin{tabular}{lllll}
\hline Patient group & $\begin{array}{l}\text { Duration of } \\
\text { therapy (months) }\end{array}$ & Gall stones & No gall stones & Total \\
\hline Untreated & $-11 \cdot 7(4-18)$ & 6 & 32 & 38 \\
Treated (prospective) & 2 & 19 & 21 \\
Treated (retrospective) & $30(3-59)$ & 11 & 7 & 18 \\
\hline
\end{tabular}

Statistics

Results are expressed as means (SEM). The prevalence of gall stones was assessed by $\chi^{2}$ analysis. Differences between the acromegalic groups and normal controls were compared using the Wilcoxon rank sum test. Differences in the paired data were assessed with the Wilcoxon signed rank test.

\section{Results}

\section{GALL STONE FORMATION}

Table II details the number of gall stones found in each patient group. Six (16\%) of the 38 untreated acromegalic patients had gall stones. This figure is just significantly different to that predicted for a group of people of the same age and sex in the general population using the Bristol prevalence data (2.5 cases predicted, $\mathrm{p}<0.05),{ }^{8}$ but is not significantly different to that similarly calculated from the Sirmione, Italy data ( 3.7 cases predicted). ${ }^{9}$ The median plasma growth hormone concentration ( $\mathrm{mU} / \mathrm{l})$ on a five-point day curve was not significantly different in patients with gall stones $(26 \cdot 5$, range $18 \cdot 7$ to 1135$)$ compared with those without (38.9, range 5.4 to 294 ).

Thirteen (34\%) of the 39 acromegalic patients taking octreotide for a mean of 20 months (range 3-62) had gall stones. This is significantly different to the prevalence in patients not taking octreotide $(p<0.005)$. Two new cases of gall stones occurred in the 21 prospectively studied patients. Gall stones were first found after 15 and 16 months follow up, previous scans at 5 and 10 months and at 6 and 12 months respectively had been normal.

Among retrospectively studied patients, who had been treated with octreotide, $11(61 \%)$ of the 18 had gall stones. This prevalence is much higher $(\mathrm{p}<0.001)$ than that predicted for the general population of the same age and sex using the published prevalence data in the general population $(1 \cdot 2$ cases predicted using the Bristol data $^{8} ; 1.6$ cases predicted using Sirmione data ${ }^{9}$ ). Within these retrospectively studied patients, all but two of the subgroup of eight patients who had been on therapy with octreotide for over 36 months) mean 45.5 months, range 37-59) developed gall stones. The mean (SEM) daytime plasma growth hormone concentration (mU/l) measured on octreotide therapy was not significantly different in patients with gall stones $(12 \cdot 9$ $(3 \cdot 2))$ compared with those without $(18 \cdot 0(7 \cdot 5))$. Five of the patients with gall stones were scanned repeatedly. In all five, the number and size of the stones increased over a 12-18 month period. To date, no patient has had symptoms referrable to their gall stones.

\section{Gall bladder motility}

Fasting and postprandial residual gall bladder volumes and maximal percentage emptying after the liquid meal in normal subjects and untreated and treated acromegalic patients are given in Table III. Exclusion of the data of the five acromegalic patients studied who had gall stones did not affect the results. Maximal percentage gal bladder emptying for the different groups, in- 
TABLE III Parameters of gall bladder emptying in normal subjects, untreated acromegalic patients and acromegalic patients treated with octreotide. (Values mean (SEM))

\begin{tabular}{lcll}
\hline $\begin{array}{l}\text { Gall bladder } \\
\text { measurement }\end{array}$ & $\begin{array}{l}\text { Normal } \\
\text { subjects } \\
(n=19)\end{array}$ & $\begin{array}{l}\text { Untreated } \\
\text { acromegalic patients } \\
(n=31)\end{array}$ & $\begin{array}{l}\text { Treated } \\
\text { agromegalic patients } \\
(n=15)\end{array}$ \\
\hline $\begin{array}{l}\text { Fasting gall bladder } \\
\text { volume (ml) }\end{array}$ & $26 \cdot 2(2 \cdot 6)$ & $33 \cdot 6(2 \cdot 7)$ & $45 \cdot 0(3 \cdot 0)$ \\
$\begin{array}{l}\text { Residual gall bladder } \\
\text { volume (ml) }\end{array}$ & $9 \cdot 0(0 \cdot 9)$ & $21 \cdot 7(2 \cdot 1)^{\star}$ & $36 \cdot 8(3 \cdot 9)^{\star} \dagger$ \\
$\begin{array}{l}\text { Maximal gall bladder } \\
\text { emptying }(\%)\end{array}$ & $64 \cdot 0(2 \cdot 8)$ & $34 \cdot 2(4 \cdot 0)^{\star}$ & $21 \cdot 2(5 \cdot 9)^{\star}$ \\
\hline
\end{tabular}

${ }^{\star} \mathrm{p}<0.001$ compared with normal subjects; $\nmid \mathrm{p}<0.001$ compared with untreated acromegalic patients.

cluding the subjects with gall stone disease is given in Figure 1. Gall bladder emptying was significantly impaired in the untreated acromegalic patients and acromegalic patients on octreotide, and similar to that in gall stone patients. There was no significant difference in maximal percentage emptying in the octreotide treated group of acromegalic patients and those not taking octreotide. The rate of gall bladder emptying in untreated acromegalic patients was significantly less than in the normal controls (rate constant $-0.015 /$ minutes $v-0.040 /$ minutes, $\mathrm{p}<0.001)$. Treatment with octreotide reduced the rate of emptying still further (rate constant $-0.006 /$ minutes, $p<0.05$ ) and significantly increased postprandial residual gall bladder volume. Although the control group was younger (mean age 37 years) than the acromegalic patients (mean age 48 years), the subset of the older normal subjects (eight in all) with a mean age of 51 years had similar results to the normal group as a whole.

Nine of the acromegalic patients had gal bladder motility studies performed before and after treatment with octreotide, and the effect on gall bladder fasting and residual volume is shown in Figure 2. Fasting volume increased with octreotide in seven of the nine patients (mean (SEM) of group $40.6(7 \cdot 0) \mathrm{ml}$ to $48 \cdot 7(3 \cdot 8) \mathrm{ml}$ ). This was not statistically significant. Residual volume however increased in all but one of the patients (mean (SEM) of the group 25.9 $(5 \cdot 3) \mathrm{ml}$ to $39 \cdot 1(4 \cdot 6) \mathrm{ml}, \mathrm{p}<0 \cdot 05)$.

\section{Discussion}

This study shows that acromegalic patients who are not treated with octreotide have a similar gall

Figure 1: Maximal gall bladder emptying after a liquid test meal in normal $(N)$, untreated acromegalic patients $(A)$, acromegalic patients taking octreotide (AO), and gall stone patients $(G S)$. Means of the groups are represented. Gall bladder emptying in $A, A O$, and $G S$ groups was significantly impaired compared with that in normal controls $(p<0.001)$.

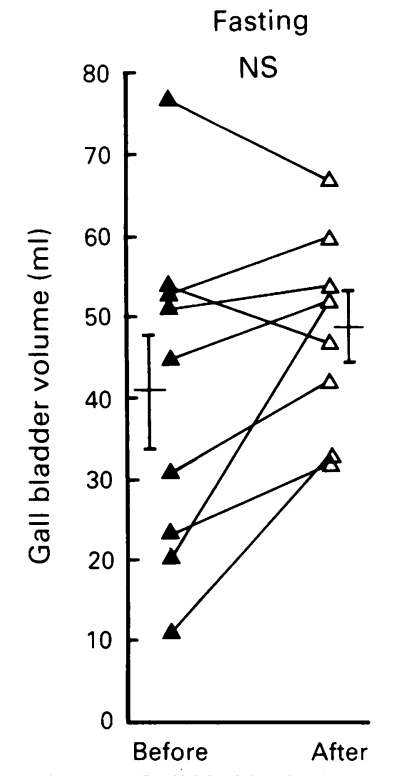

Residual $p<0.05$

(a) 2: Gall bladder fasting and residual volumes in acromegalic patients before $(\boldsymbol{\Delta})$ and after treatment with octreotide $(\triangle)$. Means $(S E M)$ are represented.

stone prevalence to the general population and that treatment with octreotide is associated with gall stone formation. Long term octreotide therapy might be expected to increase the risk of gall stone formation for several reasons. Tumours secreting large amounts of native somatostatin are associated with the 'somatostatinoma syndrome' caused by the biological effects of excessive somatostatin production; six of seven such patients described by Krejs et al had gall stones, ${ }^{4}$ and 25 of the 27 patients reported so far with pancreatic somatostatinoma have had gall stones. ${ }^{13}$ Somatostatin has several actions that may predispose to cholelithiasis. Firstly, gall bladder contraction in response to exogenous cholecystokinin ${ }^{14}$ and meal stimuli is impaired. ${ }^{15}$ Somatostatin has an inhibitory effect on cholecystokinin release ${ }^{1617}$ and also on acetylcholine release from the gall bladder myenteric plexus upon which cholecystokinin is partly dependent for its action. ${ }^{18}$ Secondly, somatostatin has an anticholeretic action, reducing fasting hepatic bile production in both man and dog. ${ }^{19-21}$ The effect of somatostatin (and its analogues) on bile composition is not well defined. In a study by Ahrendt $e t a l^{22}$ using a prairie dog model, octreotide not only induced gall bladder stasis but also altered bile composition, possibly making the bile more prone to stone formation. This is supported by Hussaini $e t a l$ who have shown that some of the acromegalic patients reported in their study who developed gall stones while taking octreotide have abnormally lithogenic bile. ${ }^{23}$

A high prevalence of gall stones has indeed been reported in acromegalic patients treated with octreotide, ${ }^{672+25}$ together with poor gall bladder contraction, ${ }^{26}$ but the incidence of gall stones, and gall bladder motor function in untreated acromegalic patients has not been previously studied. In a report of the effect of octreotide on gall bladder motility in five acromegalic patients maintained on octreotide for 6-32 months, van Liessum et al showed that octreotide completely suppressed gall bladder contraction after a Lundh meal. ${ }^{26}$ Chole- 
cystokinin release after the meal was attenuated by octreotide but still occurred. This is in contrast to the acute study showing total inhibition of cholecystokinin release and suggests that there is partial escape of cholecystokinin release during chronic octreotide therapy from the suppressing action of octreotide.

Our data confirm previous reports that octreotide therapy is associated with an increased prevalence of gall stones and show that the duration of treatment with octreotide is important in the risk of stone formation. The high prevalence of gall stones in the retrospectively studied group is particularly convincing. Data from this group of patients suggest that the risk of gall stone formation within the first year of octreotide treatment is slight, but that this increases with time, such that gall stones are present in $75 \%$ of patients when treatment is continued for more than 3 years. The risk of gall stone formation with octreotide therapy has been reported to be quite low in some studies, ${ }^{27}{ }^{28}$ and the timing of the octreotide administration in relation to meals may be an important factor. Octreotide administration after meals may result in a less profound effect on gall bladder emptying. Our patients, however, have a high prevalence of gall stones despite being instructed to take their second and third injections of octreotide mid-afternoon and late in the evening and since even small doses (in the order of $5 \mu \mathrm{g}$ ) are capable of suppressing meal stimulated gall bladder contraction for up to 6 hours, ${ }^{29}$ it may not be possible to avoid the effect of octreotide on gall bladder motor function.

The prevalence of gall stones in the untreated acromegalic subjects is at the most only slightly greater than that in the normal population despite the fact that gall bladder function in this group is severely impaired and of the order of that found in patients with cholesterol gall stone disease..$^{30-32}$ The reason for impaired gall bladder emptying in these subjects is not clear: delayed gastric emptying may be important, although since the time course of gall bladder emptying and refilling after the liquid meal was similar in both the untreated acromegalic patients and the normal controls it seems unlikely that this is a major factor.

In conclusion, our study has confirmed previous work that shows that octreotide therapy is associated with an increased prevalence of gall stones and that duration of treatment seems to be important. Impaired gall bladder emptying is associated with this increased risk. We have also shown, for the first time, that acromegalic patients not treated with octreotide have abnormal gall bladders which empty poorly. The reason for this is as yet undetermined.

We would like to thank the Rahere Association and the Joint Research Board of St Bartholomew's Hospital for their generous support. We are grateful to Professor R H Dowling for his helpful advice in the preparation of this manuscript.

1 Besser GM, Mortimer CH, Carr D, Schally AV, Coy DH, Evered D, et al. Growth hormone release inhibiting hormone in acromegaly. BMF 1974; 1: 352-5.

2 Wass JAH. Somatostatin and its physiology in health and disease. In: Clinical neuroendocrinology. New York: disease. In: Clinical neuroend
Academic Press, 1982: 359-95.

3 Lamberts SWJ, Uitterlinden P, Verschoor L, Van Dongen KJ, Del Pozo E. Long-term treatment of acromegaly with the somatostatin analogue SMS 201-995. N Engl f Med 1985; 313: 1576-80.

4 Krejs GJ, Orci L, Conlon M, Ravazzola M, Davis GR, Raskin $\mathrm{P}$, et al. Somatostatinoma syndrome. N Engl F Med 1979; 301: 285-92.

5 Ewins DL, Javaid A, Coskeran P, Deprez PM, Barrett JJ, McGregor AM. Assessment of gall bladder dynamics and the development of gall stones during octreotide therapy for acromegaly. [Abstract.] $\mathcal{F}$ Endocrinol Invest 1991; 14 (suppl 1): 43 .

6 Page MD, Millward ME, Taylor A, Preece M, Hourihan M Hall R, et al. Long-term treatment of acromegaly with a long-acting analogue of somatostatin, octreotide. $Q \mathcal{F} \mathrm{Med}$ 990; 274: 189-201.

7 McKnight JA, McCance DR, Sheridan B, McIlrath E, Hadden DR, Kennedy L, et al. A long-term dose-response study of somatostatin analogue (SMS 201-995, octreotide) in resistant acromegaly. Clin Endocrinol 1991; 34: 119-25.

8 Heaton KW, Braddon FEM, Mountford RA, Hughes AO Emmett PM. Symptomatic and silent gall stones in the community. Gut 1991; 32: 316-20.

9 Barbara L, Sama C, Labate AMM, Taroni F, Rusticali AG, Festi $\mathrm{D}$, et al. A population study on the prevalence of gall stone disease: The Sirmione study. Hepatology 1987; 7 : 913-7.

10 Everson GT, Braverman DZ, Johnson ML, Kern F Jr. A critical evaluation of real-time ultrasonography for the study 1980; 79: 40-6.

11 Dodds WJ, Groh WJ, Darweesh RMA, Lawson TL, Kishk SMA, Kern MK. Sonographic measurement of gall bladde volume. Am $\mathcal{F}$ Roentgenol 1985; 145: 1009-11.

12 Everson GT, McKinley C, Lawson M, Johnson M, Kern F Jr. Gall bladder function in the human female: Effect of the ovulatory cycle, pregnancy, and contraceptive steroids. Gastroenterology 1982; 82: 711-9.

13 Vinik AI, Moattari AR. Treatment of endocrine tumours of the pancreas. In: Barkan $\mathrm{AB}$, ed. Endocrinology and metabolism clinics of North America. Philadelphia: WB Saunders, 1989: 500-4.

14 Gullo L, Bolondi L, Scarpignato C, Priori P, Casanova P, Labo G. Effect of somatostatin and thyrotropin-releasing hormone on cholecystokinin-induced gall bladder emptyhormone on cholecystokinin-induced

15 Fisher RS, Rock E, Levin G, Malmud LS. Effects of somatostatin on gall bladder emptying. Gastroenterology 1987; 92: 885-9.

16 Schlegel W, Raptis S, Harvey RF. Inhibition of cholecy stokinin-pancreozymin release by somatostatin. Lancet 1977; ii: $166-8$.

17 Reichlin S. Somatostatin. N Engl f Med 1984; 309: 1495-501.

18 Guillemin R. Somatostatin inhibits the release of acetylcholine induced electrically in the myenteric plexus. Endocrinology 1976; 99: 1653-4.

19 Magnusson I, Einarsson K, Angelin B, Nyberg B, Bergstrom $\mathrm{K}$, Thulin L. Effects of somatostatin on hepatic bile K, Thulin L. Effects of somatostatin on

20 Hanks JB, Kortz WJ, Andersen DK, Jones RS. Somatostatin suppression of canine fasting bile secretion. Gastroenterology 1983; 84: 130-7.

21 Rene E, Danzinger RG, Hofmann AF, Nakagaki M. Pharmacologic effect of somatostatin on bile formation in the dog. Gastroenterology 1983; 84: 120-9.

22 Ahrendt SA, Mcguire GE, Pitt HA, Lillemoe KD. Why doe somatostatin cause gallstones. Am F Surg 1991; 161: 177-83.

23 Hussaini SH, Murphy GM, Kennedy C, Wass JAH, Besser GM, Dowling RH. Pathogenesis of octreotide (ot)associated gall bladder stones (gbs) in acromegaly. [Abstract.] Gut 1992; 33: S26.

24 Sassolas G, Harris AG, James-Deidier A. French SMS 201-995/Acromegaly Study Group. Long term effect of incremental doses of the somatostatin analogue SMS incremental doses of the somatostatin analogue SMS $201-995$ in 58 acron
$1990 ; 71: 391-7$.

25 Plockinger U, Dienemann D, Quabbe H-J. Gastrointestinal side-effects of octreotide during long-term treatment of acromegaly. F Clin Endocrinol Metab 1990; 71: 1658-62.

26 van Liessum PA, Hopman WP, Pieters GF, Jansen JBMJ, Smals AGH, Rosenbusch G, et al. Postprandial gall bladder motility during long term treatment with the long-acting somatostatin analog SMS 201-995 in acromegaly. F Clin Endocrinol Metab 1989; 69: 557-62.

27 Tauber JP, Babin Th, Tauber MT, Vigoni F, Bonafe A, Ducasse $M$, et al. Long term effects of continuous subcutaneous infusion of the somatostatin analogue octreotide in the treatment of acromegaly. 7 Clin Endocrinol Metab in the treatment

28 Lamberts SWJ. The role of somatostatin in the regulation of anterior pituitary hormone secretion and the use of its analogs in the treatment of human pituitary tumours. Endocr Rev 1988; 9: 417-36

29 Zhu X-F, Shi Y-F, Qin D, Zhang J-X, Harris AG. Effect of small doses of somatostatin analogue, octreotide, on gall bladder contractility in normal Chinese adults. Dig Dis $S_{c i}$ 1992; 37: 105-8.

30 Forgacs IC, Maisey MN, Murphy GM, Dowling RH. Influence of gall stones and ursodeoxycholic acid therapy on gall bladder emptying. Gastroenterologv 1984; 87: 299-307.

31 Fisher RS, Stelyer F, Rock E, Malmud LS. Abnormal gall bladder emptying in patients with gallstones. Dig Dis Si 1982; 27: 1019-24.

32 Pomeranz IS, Shaffer EA. Abnormal gall bladder emptying in a subgroup of patients with gall stones. Gastroenterology $1985 ; 88$ : 787-91. 